\title{
PENGARUH MOTIVASI DAN LINGKUNGAN KERJA TERHADAP KINERJA APRATUR SIPIL NEGARA PADA DISDUKCAPIL KABUPATEN HUMBANG HASUNDUTAN
}

\author{
THE INFLUENCE OF MOTIVATION AND THE WORK ENVIRONMENT ON THE PERFORMANCE OF \\ STATE CIVIL SERVANTS IN DISDUKCAPIL HASUNDUTAN HUMBANG DISTRICT
}

\author{
Abdi Sugiarto*)1, Ronita Panjaitan**) \\ ${ }^{*}$ Fakultas Ekonomi dan Bisnis,Universitas Tjut Nyak Dhien \\ Jl. Rasmi, No 28, Medan, Sumatera Utara, 20123, Indonesia \\ ${ }^{* * *}$ Fakultas Ekonomi, Universitas HKBP Nomensen \\ Jl. Sutomo, No. 4A, Medan Sumatera Utara, 20234, Indonesia
}

\begin{abstract}
The majority of residents of Humbang Hasudutan Regency are farmers, whose routine is different from the ASN routine. Based on environmental culture, the perspective of motivation on employees and the comfort of the work environment is certainly different. Based on this phenomenon, this study aims to analyze the motivation and work environment on the performance of ASN in the Disdukcapil environment of Humbang Hasundutan Regency. This type of research is a causative research with a population of 65 people and with a saturated sampling method. Data analysis through several preliminary stages, classical assumption test, regression equation analysis, and hypothesis testing with $t$ test and $F$ test. Instruments with 24 questions to measure work motivation, work environment and employee performance have been declared valid and reliable. After going through statistical tests, it shows that motivation and work environment have a positive and significant effect on the performance of ASN Disdukcapil Humbang Hasundutan both simultaneously and partially. However, to optimize the performance of civil servants, it is necessary to explore other factors so that the performance of Disdukcapil Humbang Hasundutan Regency reaches a very good category. Adjustment of local culture also needs to be adjusted to the needs and habits of ASN Disdukcapil Humbang Hasundutan.
\end{abstract}

Keywords: motivation, work environment, performance of civil servants, hasundutan, regression

\begin{abstract}
Abstrak: Mayoritas penduduk Kabupaten Humbang Hasudutan adalah petani yang notabene rutinitasnya berbeda dengan rutinias ASN. Berdasarkan budaya setempat perspektif motivasi atas kebutuhan pegawai dan kenyamanan lingkungan kerja tentu berbeda. Berdasarkan fenomena ini, penelitian ini bertujuan menganalisis pengaruh motivasi dan lingkungan kerja terhadap kinerja ASN di lingkungan Disdukcapil Kabupaten Humbang Hasundutan. Jenis penelitian ini merupakan penelitian kausatif dengan populasi 65 orang dan dengan metode sampling jenuh. Analisis data melalui beberapa tahap pendahuluan, uji asumsi klasik, analisis persamaan regresi, dan pengujian hipotesis dengan uji t dan uji F. Instrumen dengan 24 pertanyaan untuk mengukur motivasi kerja, lingkungan kerja dan kinerja pegawai telah dinyatakan valid dan reliabel. Setelah melalui serangkaian uji statistik, disimpulkan bahwa motivasi dan lingkungan kerja berpengaruh positif dan signifkan terhadap kinerja ASN Disdukcapil Humbang Hasundutan baik secara simultan maupun secara parsial. Namun, untuk mengoptimalkan kinerja ASN perlu ditelusuri faktor lain agar capaian kinerja Disdukcapil Kabupaten Humbang Hasundutan mencapai kategori sangat baik. Penyesesuaian budaya lokal juga perlu disesuaikan dengan kebutuhan dan kebiasaan ASN Disdukcapil Humbang Hasundutan.
\end{abstract}

Kata kunci: motivasi, lingkungan kerja, kinerja ASN,hassundutan, regresi

\footnotetext{
${ }^{1}$ Alamat Korespondensi:

Email: mimoabdi2@gmail.com
} 


\section{PENDAHULUAN}

Kinerja adalah perilaku pekerja yang memberikan andil terhadap penyelesaian sasaran organisasi, baik secara positif maupun negatif (Imran et al. 2012; Wibowo, 2015). Di sisi lain kinerja merupakan hasil kerja seseorang yang diberikannya berdasarkan keterampilan, pengalaman, dan penuh tanggung jawab (Selamat dan Heryanto, 2019). Dari beberapa pendapat ini kinerja pegawai berkaitan erat dengan tujuan suatu organisasi, kinerja juga berkaitan dengan intrapersonal personal seseorang. Dengan demikian kinerja pegawai menjadi perhatian khusus dalam menjalankan roda organisasi seperti yang dilakukan pada Disdukcapil Kabupaten Humbang Hasudutan. Pelaksanaan kinerja Disdukcapil Kabupaten Humbang Hasundutan dengan menggunakan motto MANTAP (Melayani, Aktif, Netral, Terpercaya, Administratif dan Profesional). Capaian kinerja merupakan persentasi hasil penilaian kinerja pegawai (Mangkunegara, 2012) terhadap target yang ditetapkan (Prabandari dan Asri Dwija Putri, 2019), laporan capaian kinerja Disdukcapil Humbang Hasundutan dapat dilihat pada Tabel 1.

Berdasarkankan tabel di atas, pada tahun 2018 rating capaian kinerja (Afriyanti et al. 2015) mengalami sedikit penurunan, seperti pada sub capaian kinerja kepemilikan akta perkawinan dari sangat baik (97) menjadi baik (81). Namun, antara beberapa sub capaian kinerja tersebut, terdapat sub capaian kinerja yang mengalami kenaikkan yakni pada kinerja kepemilikan KPT-el dan Perekaman KTP-el. Dari empat sub capaian kinerja yang mengalami penurunan, sub capaian kinerja kepemilikan akta perkawinan merupakan sub capaian kinerja yang paling menurun $16,5 \%$.

Banyak faktor-faktor yang memengaruhi kinerja seperti, kepuasan kerja (Garaika, 2020; Muslich, 2012), motivasi (Gachengo dan Wekesa, 2017; Larasati dan Gilang, 2016; Murti dan Srimulyani, 2013), lingkungan kerja (Badrianto dan Ekhsan, 2019; Bukhari dan Pasaribu, 2019; Eliyanto, 2018; Sofyan, 2013; Sunarsi et al. 2020), Gaya kepemimpinan (Chandra dan Priyono, 2015; Priarso et al. 2019), kompensasi (Dhermawan et al. 2012), training bermakna (Ang et al. 2020) dan lain sebagainya. Beberapa faktor di atas ada faktor motivasi, motivasi merupakan topik yang perlu di bahas dalam ilmu sosial (Reiney, 2019). Selain keterampilan, kinerja seseorang tegantung pada tingkat motivasi seseorang dan motivasi juga berkaitan erat dengan kebutuhan pegawai (Seo et al. 2004; Twalib dan Kariuki, 2016). Oleh sebab itu, di dalam pemberian motivasi harus bertitik tolak dari kebutuhan pegawai itu sendiri. Motivasi merupakan sebagai proses yang menjelaskan arah, dan ketekunan seorang individu untuk mencapai tujuannya (Robbins, 2001). Lebih khusus motivasi kerja merupakan dorong yang diberikan kepada pegawai sehingga mereka berusaha sepenuh hati untuk mencapai tujuan organisasi (Larasati dan Gilang, 2016).

Motivasi muncul karena dua sumber dua sumber yakni sumber motivasi instrinsik dan motivasi ekstrinsik (Seo et al. 2004). Motivasi instrinsik yakni motivasi yang muncul dikarenakan adanya dorongan dari dalam diri pegawai, sedangkan motivasi ekstrinsik muncul karena adanya dorongan dari luar seperti lingkungan kerja yang nyaman. Oleh sebab itu, lingkungan kerja secara tidak langsung memengaruhi kinerja pegawai (Dewi dan Frianto, 2013) dan merupakan variabel yang perlu diperhatikan (Amabile dan Gryskiewicz, 1989; Siahaan dan Bahri, 2019). Namun, lingkungan kerja dapat memberikan dampak positif dan dampak negatif seperti tempat kerja di lingkungan industri (Ollukkaran dan Gunaseelan, 2012). Lingkungan kerja dikelompokkan menjadi dua bagian yakni lingkungan kerja non fisik dan lingkungan kerja fisik (Rahmawanti et al. 2014; Sudarmayanti, 2004; Wahyudi dan Suryono, 2006). Lingkungan kerja fisik merupakan semua yang terdapat disekitar tempat kerja (Elizar dan Hasrudy, 2018) yang dapat memberikan dampak kepada karyawan secara langsung maupun tidak langsung. Sementara lingkungan kerja non fisik merupakan semua situasi yang dialami sorang pegawai yang berkaitan dengan pekerjaan pegawai tersebut, serta hubungannya terhadap pegawai lainya (Sudarmayanti, 2004). Untuk mengetahui kondisi lingkungan kinerja Disdukcapill Hubang Hasudutan, pengamatan awal peneliti mengenai lingkungan kerja yang meliputi beberapa indikator, suhu ruangan, keamanan, kebersihan dan lain sebagainya (A. A. T. Budianto dan Katini, 2015; Serdamayanti, 2011; Suwondo dan Sutanto, 2015) di lingkungan Disdukcapil Humbang Hasundutan dapat dilihat pada Tabel 2. Hasil pengamatan awal ini juga bertujuan untuk memperkuat hipotesis pengaruh lingkungan kerja terhadap kinerja pegawai dan tidak gunakan untuk uji hipotesis. Pengukuran lingkungan kerja fisik menggunakan skala likert 5 titik respon (Bertram, 2017; Budiaji, 2013), dengan interpretasi presentasi skor respon (Zahro et al. 2017). 
Secara keseluruhan kondisi lingkungan kerja fisik baik, namun ada beberapa indikator dengan kondisi cukup baik yakni pada indikator, pertukaran udara, musik, dan kebisingan. Lingkungan kinerja perlu diperhatikan karena kondisi lingkungan kerja yang baik akan memberikan rasa nyaman kepada pegawai saat bekerja dengan memiliki lingkungan kerja yang kondusif pegawai dapat bekerja dengan lebih baik dan lebih fokus (Elizar dan Hasrudy, 2018). Hubungan pegawai terhadap atasan, bawahan dan sesama merupakan salah satu dari lingkungan kinerja non fisik, mereka berkomunikasi dengan baik, meluangkan waktu istirahat untuk saling menjalin hubungan, menerapkan peraturan yang sama, dan tidak ada perasaan pengecualian diri oleh seseorang pegawai. Lingkungan kinerja dapat memengaruhi atau meningkatkan motivasi (Arep dan Tanjung, 2003; Basori et al. 2017).

Motivasi kerja berfungsi sebagai pendorong kepada pegawai agar bekerja serius dan giat untuk mencapai tujuan institusi (Arianto et al. 2016; A. Budianto et al. 2017; Tanjung, 2015). Secara umum motivasi kerja dipengaruhi oleh individual dan organisasi (Gomes, 2003). Kabupaten Humbang Hasudutan dengan penduduk mayoritas petani, sebagai warga Humbang Hasudutan, seorang pegawai harus berinteraksi dengan warga setempat demi kebutuhan Sosial dan kebutuhan rasa aman (Iskandar, 2016; Maslow, Abraham, 1984). Mengikuti kebisaan-kebiasaan budaya lokal merupakan wujud dari mendekatkan diri kepada masyarakat, disamping itu karakteriktik masyarakat yang mayoritas suku batak yang menjunjung nilai-nilai kekeluargaannya (Tinambunan, 2010).
Masih adanya capaian kinerja yang dibawah kriteria sangat baik, tentunya ini menjadi perhatian khusus bagi pimpinan. Faktor apa saja yang mempengaruhi kinerja pegawai di lingkungan Disdukcapil Humbang Hasundutan. Beberapa teori dan di beberapa instansi pemerintahan menyebutkan motivasi dan lingkungan kerja merupakan faktor yang mempengaruhi kinerja pegawai, namun apakah sama halnya di lingkungan Disdukcapil Humbang Hasundutan mengingat budaya, adat-istiadat dan karakteristik penduduk yang berbeda. Dapat mendukung pimpinan terkait dalam menentukan kebijakan yang tepat sasaran untuk meningkatkan capaian kinerja pegawainya merupakan tujuan yang diharapkan dari hasil penelitian ini.

Untuk mengungkapkan secara rinci fenomena yang ada di Disdukcapil Kabupaten Humbang Hasundutan, mengenai pengaruh motivasi dan lingkungan kerja terhadap kinerja ASN merupakan tujuan dari penulisan artikel ini. Sehingga kesimpulan dari penelitian ini menjadi referensi pemangku kebijakan dalam menentukan keputusan, seperti meningkatkan motivasi ASN atau meningkatkan lingkungan kerja yang aman dan nyaman atau keputusan yang lain. Bagaimanapun tingkat kinerja ASN perlu dipantau dan dikontrol guna mendukung dinas terkait untuk mencapai good government. Cakupan dari penelitian ini, sematamata menjelaskan berapa besar dampak motivasi kerja dan lingkungan kerja terhadap performance ASN di lingkungan Disdukcapil Kabupaten Humbang Hasundutan.

Tabel 1. Laporan capaian kinerja Disdukcapil Humbang Hasundutan

\begin{tabular}{lccc}
\hline Indikator Kinerja & 2016 & 2017 & 2018 \\
\hline Kepemilikan KK & 96 & 97 & 95 \\
Perekaman KTP-el & 83 & 94 & 93 \\
Kepemilikan KTP-el & 97 & 95 & 98 \\
Kepemilikan Akta Kelahiran & 95 & 86 & 91 \\
Kepemilikan Akta Perkawinan & 89 & 97 & 81 \\
Kepemilikan Akta Kematian & 95 & 91 & 87 \\
\hline
\end{tabular}

Tabel 2. Lingkungan kerja fisik

\begin{tabular}{lc}
\hline Indikator Lingkungan Kerja & Kondisi \\
\hline Pengecatan & Baik \\
Kebersihan & Baik \\
Pertukaran udara & Cukup Baik \\
Penyinaran & Baik \\
Music & Cukup Baik \\
Keamanan & Baik \\
keributan & Cukup Baik \\
\hline
\end{tabular}




\section{METODE PENELITIAN}

Penelitian ini dimulai pada bulan Mei 2019 sampai dengan bulan November 2019. Penelitian ini dilakukan di lingkungan Dinas Kependudukan dan Pecacatan Sipil Kabupaten Humbang Hasundutan yang beralamat jl. Sisingamangaraja XII KM 2,5 Kompleks Perkantoran Tano Tubu Doloksanggul. Populasi penelitian ini adalah ASN di lingkungan Disdukcapil Humbang Hasundutan yang berjumlah 65 pegawai. Metode pemilihan sampel menggunakan metode sampling jenuh (Muhammad, 2015).

Penelitian ini termasuk penelitian kausatif (causative), karena menganalisis pengaruh beberapa variabel terhadap variabel lainnya (Nofrita, 2013). Penelitian kausatif bertujuan untuk mengkaji dampak antar variabel (Putra, 2013). Jenis datanya yang digunakan data subjektif(Putra, 2013) dan berasal dari sumber data primer (Putra, 2013). Data primer diperoleh melalui instrumen wawancara dan kuesioner. Kuesioner disusun dengan beberapa pertanyaan; 8 pertanyaan untuk motivasi; 8 pertanyaan untuk lingkungan kerja dan 8 pertanyaan untuk kinerja pegawai. Selain data primer dalam penelitian ini juga menggunakan data skunder yang diperoleh dari. Profil Disdukcapil, rekapitulasi absen dan laporan capaian kinerja tahun 2016-2018

Uji hipotesis menggunakan persamaan regresi berganda dengan motivasi kerja $\left(\mathrm{X}_{1}\right)$, linkungan kerja $\left(\mathrm{X}_{2}\right)$ sebagai variabel bebas dan kinerja ASN (Y) sebagai variabel terikat. Dengan demikian, persamaan regresi berganda di bawah ini.

$$
\widehat{\mathrm{Y}} \widehat{\mathrm{Y}}=\mathrm{a}+\mathrm{b}_{1} \mathrm{X}_{1}+\mathrm{b}_{2} \mathrm{X}_{2}+\mathrm{e}
$$

Dengan hipotesis

$\mathrm{H}_{0}: \beta_{1}=\beta_{2}=0$

Tidak terdapat pengaruh motivasi kerja $\left(X_{1}\right)$ dan lingkungan kerja $\left(X_{2}\right)$ secara bersama-sama terhadap kinerja ASN di Disdukcapil Kabupaten Humbang Hasundutan.

$\mathrm{H}_{1} \quad: \beta_{1} \neq \beta_{2} \neq 0$

Terdapat pengaruh motivasi kerja $\left(X_{1}\right)$ dan lingkungan kerja $\left(X_{2}\right)$ secara bersama-sama terhadap kinerja ASN di Disdukcapil Kabupaten Humbang Hasundutan.
Sebelum melakukan uji hipotesis, dilakukan uji asumsi klasisik yang terdiri beberapa uji yakni; (1) Uji Normalitas; (2) Uji Heterokedastisitas; dan (3) Uji multoklinieritas. Kemudian melakukan analisis regresi dan uji hipotesis yang terdiri dari; Uji simultan dengan F-test dan Uji parsial dengan $t$-test dan dilanjutkan pada analisis koefisien determinasi $\left(\mathrm{R}^{2}\right)$.

Walaupun banyak faktor yang memengaruhi kinerja ASN di suatu instansi, hanya motivasi dan lingkungan kerja yang diprediksi mempunyai pengaruh besar terhadap kinerja ASN Humbang Hasundutan. Pemilihan dua faktor ini bukan tanpa sebab, di wilayah kabupaten Humbang Hasundutan merupakan wilayah lumbung pangan padi. Sehingga mayoritas rutinitas warganya adalah bertani, kebiasaan ini akan dianggap biasa, tetapi kebiasaan diluarnya ini akan dianggap tabuh. Kebiasaan menghabiskan waktu di satu tempat atau berkantor bisa saja dianggap tidak lazim bagi mereka. Dengan demikian dengan tidak sengaja pada pekerja kantor lebih baik terpengaruh untuk keluar dari ruang kerjanya. Sehingga akan menurunkan motivasi para ASN, jika motivasi kerja pegawai menurun dengan gaya kepemimpinan yang berbeda-berbeda pegawai tidak terlalu mempedulikan. Jika muncul masalah besar antara pegawai dan pimpinan karena kinerjanya, mereka dapat berdiskusi secara kekeluargaan membicarakan jalan keluar yang terbaik. Selain itu kenyaman tempat bekerja merupakan kebutuhan manusiawi untuk mau berlama-lama dan nyaman atas suasana dan lingkungan di tempat kerjanya. Sehingga diasumsikan kinerja ASN di Disdukcapil Kabupaten Humbang Hasundutan kemungkinan besar dipengaruhi oleh motivasi kerja dan lingkungan kerja. Kerangka pemikiran penelitian selengkapnya pada Gambar 1.

\section{HASIL}

\section{Spesifikasi Responden}

Jenis kelamin, usia, dan Pendidikan merupakan spesifikasi responden yang diamati dalam penelitian ini. Spesifikasi responden didominasi oleh kaum perempuan dan hampir setengah dari pegawai berusia 31-40 tahun, serta $69 \%$ memiiliki gelar sarjana. Jika diperhatikan dari dominasi usia pegawai yang masih produktif dan jenjang pendidikan pegawai yang mempuni, maka seharusnya dapat menhasilkan capaian kinerja yang sangat baik. Untuk lebih detail karakteristik responden dapat dilihat pada Tabel 3 . 


\section{Hasil Angket}

Tanggapan reponden terhadap kuesioner dengan 24 pertanyaan dapat dilihat pada Tabel 4. Data hasil rekapitulasi angket pada Tabel 4 untuk menjawab hipotesis dilanjutkan dengan analisis data seperti uji validitas dan uji reliabilitas instrumen sampai pada akhirnya uji hipotesis. Dari ketiga variable tidak ada responden yang menjawab sangat tidak setuju (STS), rata-rata skor ketiga variable juga tidak jauh beda, dan kategori setiap variable baik.

\section{Kevalidan dan Reliabilitas Instrumen}

Untuk melihat apakah pernyataan dari kuesioner mampu mengungkapkan seuatu yang akan diukur digunakan uji validitas. Proses pengujian validitas dilakukan dengan cara membandingkan $r_{\text {hitung }}$ dan $r_{\text {tabel}}$, dimana nilai $\mathrm{r}_{\text {hitung }}$ akan diketahui dari output Item-Total Statistic, sedangkan nilai $\mathrm{r}_{\text {tabel }}$ diperoleh dari tabel $r$ dengan derajat kebebasan $\mathrm{n}-2$ dan taraf signifikansi 0,05 sehingga diperoleh $r_{\text {tabel }}=0,2441$. Berdasarkan hasil pengujian, instrumen Motivasi $\left(\mathrm{X}_{1}\right)$ dengan 6 item pernyataan, Linkungan Kinerja $\left(\mathrm{X}_{2}\right)$ dengan 14 item penyataan dan Kinerja $(\mathrm{Y})$ dengan 8 item pernyataan dinyatakan Valid. Untuk mengetahui kehadadalan instrumen melalui iji reliabilitas. Jika jawaban seseorang terhadap pertanyaan adalah konsisten atau stabil dari waktu ke waktu, maka instrumen dikatakan handal atau reliable. Metode uji reliabilitas dengan metode Cronbach Alpha dan dengan syarat pengambilan keputusan, dikatakan reliabel jika Cronbach Alpha> 0,60. Dari hasil pengujian diperoleh tingkat reliabelitas instrumen motivasi, instrumen lingkungan kerja dan instrumen kinerja berturut-turut adalah 0,793; 0,754; dan 0,740 . Ketiga instrumen tersebut memiliki niliai Cronbach Alpah yang tidak lebih dari 0,60, sehingga ketiga instrumen tersebut dapat dikatakan reliabel atau handal.

\section{Uji Asumsi Klasik}

Tahapan sebelum proses uji hipotesis, terlebih dahulu dilakukan uji asumsi klasik yang terdiri dari beberapa uji yakni, uji normalitas, uji heterokedasitisan, dan uji multikolinieritas. Tujuan uji normalitas adalah untuk melihat apakah data berdistribusi normal? Analisis kenormalitasan data menggunakan bantuan SPSS, dengan kriteria pengambilan keputusan hanya dengan melihat Normal Parameter ${ }^{\text {ab }}$, jika nilai Normal Parameter $^{\mathrm{a}, \mathrm{b}}>0,05$ maka data tidak berdistribusi normal, tetapi jika nilai Normal Parameter ${ }^{\mathrm{a}, \mathrm{b}}<0,05$, maka data berdistribusi normal. Setelah menginput data kemudian melakukan operasi analisis dan diperoleh Output seperti Gambar 2.

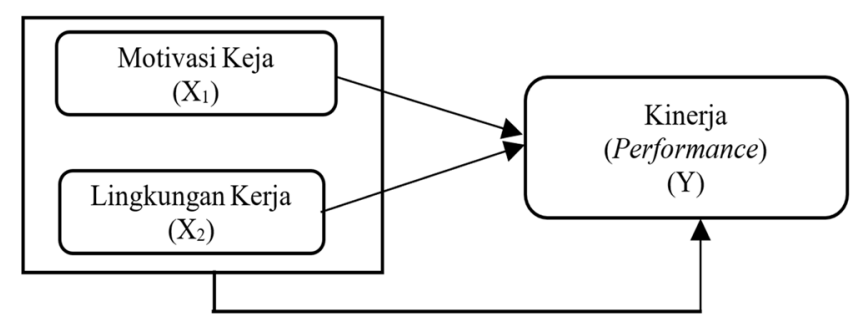

Gambar 1. Kerangka pemikiran penelitian

Tabel 3. Karakteristik responden penelitian

\begin{tabular}{lll}
\hline Aspek & Karakteristik & Persentasi (\%) \\
\hline Jenis Kelamin & Laki-laki & $44 \%$ \\
& Perempuan & $56 \%$ \\
Usia (Tahun) & $<20$ tahun & $0 \%$ \\
& $20-30$ tahun & $9 \%$ \\
& $31-40$ tahun & $52 \%$ \\
& $41-50$ tahun & $30 \%$ \\
Jenjang Pendidikan & 50> tahun & $9 \%$ \\
& SMA & $11 \%$ \\
& D3 & $17 \%$ \\
& S1 & $69 \%$ \\
& S2 & $3 \%$ \\
\hline
\end{tabular}

Tabel 4. Hasil angket

\begin{tabular}{|c|c|c|c|c|c|c|c|c|}
\hline \multirow[t]{2}{*}{ Variabel } & \multicolumn{5}{|c|}{ Persentase Respon (\%) } & \multirow{2}{*}{$\begin{array}{c}\text { Rata-Rata } \\
\text { Skor }\end{array}$} & \multirow{2}{*}{$\begin{array}{c}\text { Perolehan } \\
\text { Skor }(\%)\end{array}$} & \multirow[t]{2}{*}{ Kategori } \\
\hline & SS & $\mathrm{S}$ & RG & TS & STS & & & \\
\hline Motivasi (X1) & 15,82 & 24,28 & 55,66 & 3,71 & 0,00 & 3,53 & 70,55 & Baik \\
\hline Lingkugan Kerja (X2) & 18,35 & 22,07 & 55,08 & 4,49 & 0,00 & 3,54 & 70,86 & Baik \\
\hline Kinerja (Y) & 20,12 & 30,08 & 45,31 & 4,49 & 0,00 & 3,66 & 73,16 & Baik \\
\hline
\end{tabular}


Jika diperhatikan Output SPSS, nilai Normal Parameters $<0,05$ maka data berdistribusi normal. Selanjutnya, untuk melihat apakah model regresi terdapat ketidaksamaan varians residual dari antar pengamat maka digunakan uji heteroskedastisitas. Jika varian dari residual antar pengamat tidak tetap maka diduga terdapat problem pada uji heteroskedastisitas. Proses uji heterokedasitisitas dengan melihat grafik scatter plot apakah membentuk pola tertentu, jika membentuk pola tertentu maka tidak terdapat masalah heterokedastisitas dari model regresi tersebut.

Jika diperhatikan Gambar 3 maka data membentuk pola tertentu sehingga dapat disimpulkan bahwa model regresi ini tidak terjadi masalah heteroskedastisitas. Uji multikolinieritas bertujuan untuk mengetahui apakah terdapat hubungan yang kuat (korelasi yang kuat) antar variabel independen. Model regresi yang tepat sebaiknya tidak terdapat hubungan antara variabel bebas. Multikolinieritas dapat dilihat tingkat tolerance yang berbanding terbalik dari tingkat VIF. Tingkat VIF tinggi setara dengan tingkat tolerance rendah dan tingkat VIF yang tinggi memperlihatkan adanya kolinieritas yang tinggi. Interpretasi yang digunakan dengan melihat tingkat tolerance lebih besar dari 0,10 atau tingkat VIF di bawah 10. Hasil uji multikolinieritas dapat dilihat pada Gambar 4. Dari hasil Output multikolineritas kedua variabel bebas Motivasi $\left(\mathrm{X}_{1}\right)$ dan Linkungan Kerja $\left(\mathrm{X}_{2}\right)$ diperoleh nilai $\mathrm{VIF}<10$ dan Tolenrance $>0,1$, maka dapat disimpulkan bahwa variabel independen tidak bekorelasi.

Selanjutnya analisis koefisien persamaan regresi, outputnya dapat dilihat pada Gambar 5. Interpretasi dari hasil output koefisien persamaan regresi sebagai berikut; (1) Konstanta sebesar 42,576 yang artinya adalah jika diasumsikan tidak terjadi perubahan atau pada motivasi dan lingkungan kerja maka kinerja pegawai sebesar 42,567; (2) Jika variabel Motivasi naik sebesar 1 satuan maka kinerja naik sebesar 0,593 dengan asumsi variabel lain konstan; dan (3) Jika variabel lingkungan kerja naik sebesar 1 satuan maka kinerja naik sebesar 0,518 dengan asumsi variabel lain konstan.
One-Sample Kolmogorov-Smirnov Test

\begin{tabular}{|c|c|c|}
\hline & & Unstandardized Residual \\
\hline $\begin{array}{l}\text { N } \\
\text { Normal Parameters }{ }^{a, b} \\
\text { Most Extreme Differences } \\
\text { Test Statistic } \\
\text { Asymp. Sig. (2-tailed) }\end{array}$ & $\begin{array}{l}\text { Mean } \\
\text { Std. Deviation } \\
\text { Absolute } \\
\text { Positive } \\
\text { Negative }\end{array}$ & $\begin{array}{l}65 \\
.0000000 \\
2.96280262 \\
.075 \\
.075 \\
-.038 \\
.075 \\
.200^{c, d} \\
\end{array}$ \\
\hline \multicolumn{3}{|c|}{$\begin{array}{l}\text { a. Test distribution is Normal. } \\
\text { b. Calculated from data. } \\
\text { c. Lilliefors Significance Correction. } \\
\text { d. This is a lower bound of the true signific }\end{array}$} \\
\hline
\end{tabular}

Gambar 2. Output normalitas

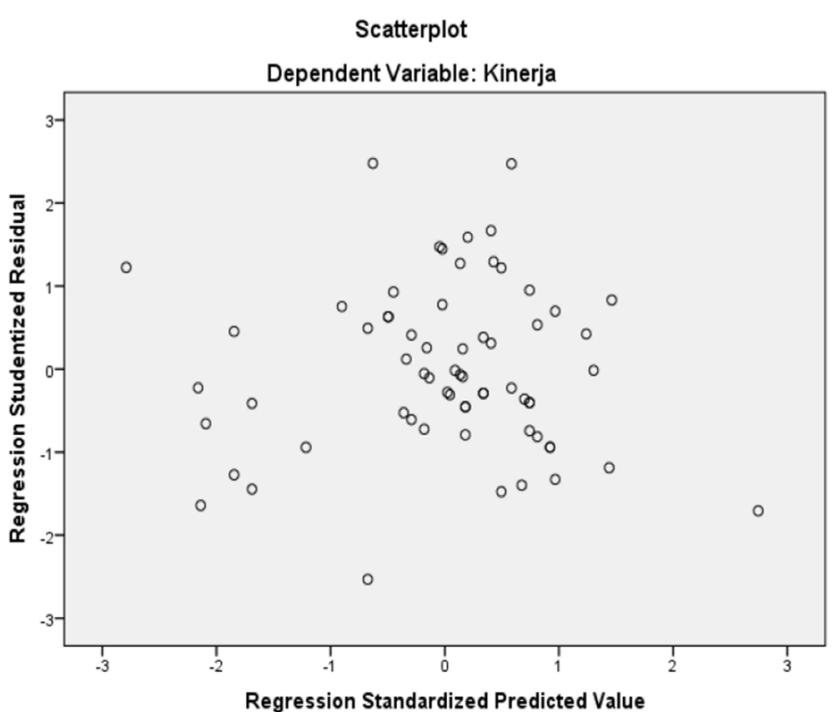

Gambar 3. Grafik scatter plot

\begin{tabular}{|l|l|l|}
\multicolumn{2}{c}{ Coefficients $^{\mathrm{a}}$} \\
\hline \multirow{2}{*}{ Model } & Collinearity & Statistics \\
\cline { 2 - 3 } & Tolerance & VIF \\
\hline 1 (Constant) & & \\
Motivasi & .975 & 1.025 \\
LingkunganKerja & .975 & 1.025 \\
\hline
\end{tabular}

a. Dependent Variable: Kinerja

Gambar 4. Output uji multikolineritas

\begin{tabular}{|l|l|l|l|}
\hline \multirow{2}{*}{ Model } & \multicolumn{3}{|c|}{ Coefficients $^{\mathrm{a}}$} \\
\cline { 2 - 4 } & $\mathrm{B}$ & Std. Error & Beta \\
\hline 1 (Constant) & 42.567 & 6.246 & \\
Motivasi & .593 & .155 & .330 \\
LingkunganKerja & .518 & .072 & .616 \\
\hline
\end{tabular}

Gambar 5. Output koeffisien persamaan regresi 


\section{Uji Hipotesis}

Uji hipotesis dilakukan sebanyak dua kali yakni untuk melihat dampak variabel independent terhadap variabel dependent secara parsial dengan uji $t$ dan untuk melihat pengaruh variabel independent terhadap variabel dependent secara simultan dengan uji F. Uji $t$ tdan uji F dianalisis menggunakan bantuan software SPSS, dengan serangkaian prosedur diperoleh salah satu tabel coefficients $^{\mathrm{a}}$ seperti pada tabel output uji t (Gambar 6) dan tabel output uji F (Gambar 7). Dari Gambar 6 diperoleh pada variabel Motivasi $t_{\text {hitung }}=3,835$ dan sig. 0,000 . Karena nilai sig. $<0,05$, maka dapat diputuskan bahwa secara signifikan motivasi berdampak positif terhadap performance pegawai. Kemudian, pada variabel lingkungan kerja diperoleh $t_{\text {hitung }}=7,153$ dan sig. 0,000, karena nilai sig. $<0,05$ maka dapat diputuskan bahwa secara signifikan lingkungan kerja berdampak positif terhadap kinerja karyawan atau pegawai. Setelah uji - $t$ dilanjutkan pada Uji-F yang merupakan uji secara simultan untuk melihat pengaruh motivasi dan lingkungan kerja terhadap kinerja Pegawai.

Pada Gambar 7 diperoleh $\mathrm{F}_{\text {hitung }}=38.198$ dan nilai sig. 0,000 , karena nilai nilai sig. $(0,00)<0,05$, maka dapat diseimpulkan bahwa motivasi dan lingkungan kerja secara simultan berpengaruh positif dan signifikan terhadap kinerja. Namun, uji statistik tidak berhenti pada uji $\mathrm{t}$ dan uji $\mathrm{F}$ saja, namun dilanjutkan pada pada analisis koefisien determinasi $\left(\mathrm{R}^{2}\right)$ untuk melihat besarnya dampak motivasi (motivation) dan lingkungan kerja terhadap performance pegawai, untuk melakukan analisis koefisien determinasi dibutuhkan Output SPSS pada Gambar 8. Berdasarkan output koefisien determinasi $\left(\mathrm{R}^{2}\right)$, variabel motivasi dan lingkungan kerja memengaruhi variabel kinerja sebesar 55,2\% sedangkan sisanya $44.8 \%$ dipengaruhi oleh variabel lain yang tidak diteliti.

Berdasarkan serangkaian hasil uji ditunjukkan bahwa motivasi memberikan dampak positif dan berarti terhadap kinerja karyawan di lingkungan Disdukcapil Humbang Hasundutan. Hal ini menunjukkan hubungan searah terhadap kinerja pegawai. Angka-angka dari hasil uji menunjukkan bahwa setiap pernyataan yang digunakan untuk mengukur hubungan antara motivasi dengan kinerja sudah mewakili persetujuan responden. Kategori perolehan skor respon terhadap angket masih pada baik, dengan demikian hal ini masih adanya kekurangan dalam motivasi yang dilakukan oleh instansi. Seperti memperhatikan disiplin para pegawai (Farisi et al. 2020) yang berkaitan dengan rutinitas dan budaya masyarakat setempat. Motivasi kerja salah satu faktor penting yang dapat mendorong seseorang karywan untuk bekerja (Farisi et al. 2020). Beberapa cara meningkat motivasi kerja dapat dilakukan dengan mempertimbangkan teori kebutuhan (Afandi, 2018). Hasil penelitian yang berkaitan dengan pengaruh positif terhadap kinerja pegawai Disdukcapil Humbang Hasudutan , sama dengan hasil yang penelitian yang telah dilakukan pada penelitian-penelitian sebelumnya (Hanafi dan Yohana, 2017; Novyanti, 2015; Permansari, 2013; Sajangbati, 2013; Sutrischastini dan Riyanto, 2017; Suwardi dan Utomo, 2011). Namun, ada beberapa hasil yang berbeda dengan hasil penelitian ini yakni penelitian yang dilakukan oleh (Fachreza, 2018).

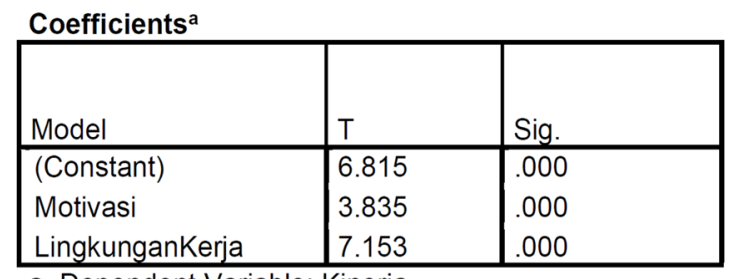

a. Dependent Variable: Kinerja

Gambar 6. Output uji t

ANOVA $^{\text {a }}$
\begin{tabular}{|l|l|l|l|l|l|l|}
\hline Model & Sum of Squares & Df & Mean Square & F & Sig. \\
\hline 1 & Regression & 692.257 & 2 & 346.128 & 38.198 & $.000^{b}$ \\
& Residual & 561.805 & 62 & 9.061 & & \\
& Total & 1254.062 & 64 & & & \\
\hline
\end{tabular}

a. Dependent Variable: Kinerja

b. Predictors: (Constant), LingkunganKerja, Motivasi

Gambar 7. Output uji F

Model Summary ${ }^{b}$

\begin{tabular}{|l|l|l|l|l|}
\hline Model & $R$ & R Square & $\begin{array}{l}\text { Adjusted R } \\
\text { Square }\end{array}$ & $\begin{array}{l}\text { Std. Error of the } \\
\text { Estimate }\end{array}$ \\
\hline 1 & $.743^{\mathrm{a}}$ & .552 & .538 & 3.010 \\
\hline
\end{tabular}

a. Predictors: (Constant), LingkunganKerja, Motivasi

b. Dependent Variable: Kinerja

Gambar 8. Output koefisien..determinasi $\left(\mathrm{R}^{2}\right)$ 
Kemudian lingkungan kerja memberikan dampak yang positif dan berarti terhadap performance pegawai di lingkungan Disdukcapil Kabupaten Humbang Hasundutan. Hal ini memperlihatkan adanya korelasi searah terhadap performance pegawai. Artinya lingkungan kerja yang baik akan meningkatkan performancee pegawai. Namun, masih adanya kekurangan dalam lingkungan kerja pada Disdukcapil Kabupaten Humbang Hasundutan, hasil kuesioner menunjukkan kriteria baik. Berkaitan dengan aspek kebersihan, pimpinan dapat meningkatkan kedisiplinan berkaitan kebersihan, perspektif setiap pegawai tentang kebersihan berbeda-beda (Darmawan, 2016). Selain itu kenyamanan ruangan seperti warna (Hutchings, 2004; Wantoro, 2013), suhu (Rosiana, 2013) dan kerapian perlu diperhatikan.

Seoarang pegawai yang mampu menjalankan pekerjaannya dengan baik akan mencapai hasil yang optimal, jika didukung oleh situasi lingkungan kerja yang sesuai. Situasi lingkungan kerja disebut baik atau sesuai jika pegawai dapat melaksanakan tugasnya secara maksimal, sehat, nyaman, dan aman. Ketidakcocokan lingkungan kerja dan pegawai dalam waktu yang lama menuntut tenaga dan waktu yang lebih banyak sehingga tidak memperoleh sistem kerja yang efektif dan efisien. Hasil penelitian ini sejalan dengan beberapa penelitian yang telah dilakukan sebelumnya seperti; (Budianto dan Katini, 2015; Hidayat dan Taufik, 2012; Kurniawan dan Heryanto, 2019; Permansari, 2013). Namun, hasil penelitian juga ada yang tidak sejalan seperti penelitian yang dilakukan oleh (Hanafi dan Yohana, 2017; Nabawi, 2019).

Dari hasil uji simultan diperoleh nilai F sebesar 38.198, dengan demikian dapat disimpulkan bahwa motivasi dan lingkungan kerja Bersama-sama memberikan pengaruh positif dan signifikan terhadap kinerja pegawai. Pengaruh motivasi keja dan lingkungan kerja terhadap kinerja pegawai sebesar 55,2\% dan selebihnya dipengaruhi oleh variabel lain yang tidak diteliti. Diduga variabel lain tersebut seperti, gaya kepemimpinan, kompensasi, disiplin kerja, kepuasan kerja, komitmen kerja, dan beban kerja. Berdasarkan hasil analisis statistik dampak motivasi kerja terhadap performance pegawai lebih besar jika dibandingkan dengan dampak lingkungan kerja terhadap performance pegawai, sehingga diharapkan pemimpin lebih memperhatikan motivasi kerja bawahannya.

\section{Implikasi Manajerial}

Implikasi manajerial yang dapat direkomendasi kepada pimpinan di lingkungan Disdukcapil Humbang Hasundutan terkait dengan motivasi kerja, lingkungan kerja dan kinerja pegawai adalah perlu dirancang program untuk memenuhi kebutuhan batin pegawai, seperti getering family, senam pagi, dan apresiasi pimpinan kepada pegawainya. Program-program tersebut diharapkan dapat menjadi pendorong atau motivasi pegawai untuk meningkatkan kinerjanya. Sikap menghargai bawahan dan mengapresiasi setiap prestasi kerja pegawai perlu dilakukan untuk memenuhi kebutuhan akan penerimaan sosial terhadap dirinya. Selanjutnya, lingkungan kerja fisik perlu diperhatikan, untuk mengelolah tata kelola ruang kerja pegawai selain konsultan yang dilihatkan, kepala adat setempat juga harus dilihatkan untuk mengkombinasikan budaya lokal dan desain modern.

\section{KESIMPULAN DAN SARAN}

\section{Kesimpulan}

Kesimpulan yang dapat diputuskan adalah dampak motivasi dan lingkungan kerja bersama-sama memengaruhi performance atau kinerja pegawai Disdukcapil Humbang Hasudutan signifikan. Namun, masih membuka peluang besar terhadap faktor-faktor yanglainseperti gayakepemimpinan, pelatihan pegawai, kompensasi dan kepuasan kerja. Antara motivasi dan lingkungan kinerja, dampak motivasi terhadap kinerja pegawai lebih besar dibandingkan lingkungan kerja terhadap performance atau kinerja pegawai, sehingga pimpinan dapat mengambil kebijakan yang lebih memperhatikan motivasi kerja pegawai. Motivasi internal seperti kebutuhan akan diterima dan dihargai oleh sesama pegawai dan pimpinan merupakan motivasi yang sangat diperlukan oleh pegawai Disdukcapil Humbang Hasundutan. Kebutuhan ini berkaitan dengan karakteristik masyarakat sekitar yang menjunjung tinggi arti kekeluargaan.

\section{Saran}

Beberapa saran yang dapat diberikan oleh pimpinan Disdukcapil Humbang Hasundutaan, adalah lebih memperhatikan motivasi kerja daripada lingkungan kerja pegawai. Memberikan apresiasi kepada pegawai 
yang telah mencapai target seperti pujian atau insentif atas kinerjanya dapat meningkatkan motivasi kerja pegawai.Kebutuhan sosial parapegawaijugahendaknya diperhatikan dengan cara membuat kegiatan-kegiatan yang dapat meningkatkan rasa kebersamaan atau kekeluargaan sesama pegawai dan sesama pegawai dan pimpinan berkaitan dengan budaya lokal, penerapannya tetap harus disesuaikan dengan kebutuhan dan kebiasaan pegawai. Pimpinan dapat mengangkat khas budaya lokal yang bersifat universival, seperti menggunakan warna atau ornamen-ornamen adat istiadat dalam mendekorasi bangungan di lingkungan Disdukcapil Kabupaten Humbang Hasudutan.

\section{DAFTAR PUSTAKA}

Afriyanti D, Sabanu HG, Noor F. 2015. Penilaian indeks akuntabilitas instansi pemerintah. Jurnal Tata Kelola \& Akuntabilitas Keuangan Negara 1(1):21-42. https://doi.org/10.28986/jtaken. v1i1.10

Amabile TM, Gryskiewicz ND. 1989. The creative environmentscales: Work environmentinventory. Creativity Research Journal 2(4):231-253. https://doi.org/10.1080/10400418909534321

Ang EE, Dharmayanti D, Widjaja DC. 2020. Efek intervensi training dan Coaching kebermaknaan kerja terhadap kinerja karyawan. Jurnal Aplikasi Bisnis dan Manajemen 6(3):558-570. https:// doi.org/10.17358/jabm.6.3.558

Arep I, Tanjung H. 2003. Manajemen Sumber Daya Manusia. Jakarta: Universitas Trisakti.

Arianto B, Warjio W, Tarigan U. 2016. Kepemimpinan lurah dalam meningkatkan motivasi kerja perangkat kelurahan. Jurnal Administrasi Publik: Public Administration Journal 6(2):107-122. https://doi.org/10.31289/jap.v6i2.1050

Badrianto Y, Ekhsan M. 2019. The effect of work environment and motivation on employee performance of PT. Hasta Multi Sejahtera Cikarang. JRBEE: Journal of Research in Business, Economics, and Education 1(1):6470.

Basori MA, Prahiawan W, Daenulhay. 2017. Pengaruh kompetensi karyawan dan lingkungan kerja dan terhadap kinerja karyawan melalui motivasi kerja sebagai variabel intervening. Jurnal Ekonomi 1(2):149-158.

Bertram D. 2017. Likert scales. Journal of Visual Impairment \& Blindness 111(5):488-488.https://
doi.org/10.1177/0145482X1711100511

Budiaji W. 2013. Skala pengukuran dan jumlah respon skala likert (the measurement scale and the number of responses in likert scale). Ilmu Pertanian dan Perikanan 2(2):127-133.

Budianto AAT, Katini A. 2015. Pengaruh lingkungan kerja terhadap kinerja pegawai pada PT Perusahaan Gas Negara (Persero) Tbk SBU distribusi wilayah Jakarata. Kreatif: Jurnal Ilmiah Prodi Manajemen Universitas Pamulung 3(1): 100-124.

Budianto A, Pongtuluran Y, Syaharuddin Y. 2017. Pengaruh etika kerja, motivasi kerja, dan kompensasi finansial terhadap kinerja karyawan. KINERJA 14(1):1-5. https://doi.org/10.29264/ jkin.v14i1.2472

Bukhari B, Pasaribu SE. 2019. Pengaruh motivasi, kompetensi, dan lingkungan kerja terhadap kinerja. Maneggio: Jurnal Ilmiah Magister Manajemen 2(1):89-103. https://doi. org/10.30596/maneggio.v2i1.3365

Chandra T, Priyono P. 2015. The influence of leadership styles, work environment and job satisfaction of employee performance studies in the school of SMPN 10 Surabaya. International Education Studies 9(1):131-140. https://doi.org/10.5539/ ies.v9n1p131

Dewi SK, Frianto A. 2013. Pengaruh lingkungan kerja terhadap kinerja karyawan melalui motivasi sari. Jurnal Ilmiah Manajemen 1(4):1055-1065.

Dhermawan AANVB, Sudibya IGA, Utama IWM. 2012. Pengaruh motivasi, lingkungan kerja, kompetensi, dan kompensasi terhadap kepuasan kerja dan kinerja pegawai di lingkungan kantor Dinas Pekerjaan Umum Provinsi Bali. Jurnal Manajemen, Strategi Bisnis Dan Kewirausahaan 6(2):173-184.

Eliyanto. 2018. Pengaruh motivasi kerja dan lingkungan kerja terhadap kinerja guru SMA Muhammadiyah di Kabupaten Kebumen. Jurnal Pendidikan Madrasah 3(1):169-181. https://doi. org/10.31932/jpe.v3i1.154

Elizar,HasrudyT.2018.Pengaruhpelatihan,kompetensi, lingkungan kerja terhadap kinerja pegawai. Maneggio: Jurnal Ilmiah Magister Manajemen 1(1):46-58. https://doi.org/10.30596/maneggio. v1i1.2239

Fachreza et al. 2018. Pengaruh motivasi kerja, lingkungan kerja, dan budaya organisasi terhadap kinerja karyawan dan dampaknya pada kinerja Bank Aceh Syariah di Kota Banda Aceh. Jurnal 
Magister Management 2(1): 115-122.

Farisi S, Irnawati J, Fahmi M. 2020. Pengaruh motivasi dan disiplin kerja terhadap kinerja karyawan. EKOMABIS: Jurnal Ekonomi Manajemen Bisnis 4(1):15-33. https://doi.org/10.37366/ekomabis. v1i02.31

Gachengo V, Wekesa S. 2017. Influence of motivation on employee performance: A case of national bank of Kenya. International Journal of Business Management and Social Research 3(2):179-185. https://doi.org/10.18801/ijbmsr.030217.20

Garaika G. 2020. Pengaruh Kompensasi, motivasi kerja dan kepuasan kerja sebagai variabel intervening terhadap kinerja. Jurnal Ilmiah Manajemen dan Bisnis 21(1):28-41. https://doi.org/10.30596/ jimb.v21i1.4181

Gomes FC. 2003. Manajemen Sumber Daya Manusia. Ed. ke-2. Yogyakarta: Andi.

Hanafi BD, Yohana C. 2017. Pengaruh motivasi, dan lingkungan kerja, terhadap kinerja karyawan, dengan kepuasan kerja sebagai variabel mediasi pada PT BNI Lifeinsurance. Jurnal Pendidikan Ekonomi Dan Bisnis (JPEB) 5(1):73-89. https:// doi.org/10.21009/JPEB.005.1.6

Hidayat Z, Taufik M. 2012. Pengaruh lingkungan kerja dan disiplin kerja serta motivasi kerja terhadap kinerja karyawan. Jurnal WIGA 2(1):79-97.

Hutchings J. 2004. Colour in folklore and traditionthe principles. Color Research and Application 29(1):57-66. https://doi.org/10.1002/col.10212

Imran R, Fatima A, Zaheer A, Yousaf I, Batool I. 2012. How to boost employee performance: Investigating the influence of transformational leadership and work environment in a Pakistani perspective. Middle East Journal of Scientific Research 11(10):1455-1462.

Iskandar. 2016. Implementasi teori hirarki kebutuhan Abraham Maslow terhadap peningkatan kinerja pustakawan. Khizanah Al-Hikmah: Jurnal Ilmu Perpustakaan, Informasi, dan Kearsipan 4(1):23-34.https://doi.org/10.24252/kah.v4i1a2

Kurniawan H, Heryanto H. 2019. Effect of work discipline and work environment on employee performance with work motivation as an intervening variable in department of tourism, youth, and sport of Padang District. Archives of Business Research 7(7):88-101.

Larasati S, Gilang A. 2016. Pengaruh motivasi kerja terhadap kinerja karyawan wilayah Telkom Jabar Barat Utara (Witel Bekasi). Jurnal Manajemen dan Organisasi 5(3):200-213. https://doi. org/10.29244/jmo.v5i3.12167

Mangkunegara AP. 2012. Manajemen Sumber Daya Manusia. Depok: Lembaga Pernerbit Fakultas Ekonomi - UI.

Maslow AH. 1984. Teori Motivasi dengan Ancangan Hirarki Kebutuhan Manusia (judul asli: Motivation and Personality). Nurul Imam, penerjemah. Jakarta: PT Pustaka Binaman Pressindo.

Muhammad S. 2015. Pengaruh model pembelajaran creative problem solving berbantuan maple II terhadap kemampuan pemecahan masalah matematis. Journal of Chemical Information and Modeling 6(1):91-98. https://doi.org/10.24042/ ajpm.v6i1.58

Murti H, Srimulyani VA. 2013. Pengaruh Motivasi terhadap kinerja pegawai dengan variabel pemediasi kepuasaan kerja pada PDAM Kota Madiun. JRMA Jurnal Riset Manajemen dan Akuntansi 1(1):10-17.

Muslich B. 2012. Analisis pengaruh motivasi terhadap kepuasan kerja dan kinerja pegawai Di PT. Sang Hyang Seri (Persero) Regional III Malang. Jurnal Aplikasi Manajemen 10(4):799-810.

Nabawi R. 2019. Pengaruh lingkungan kerja, kepuasan kerja dan beban kerja terhadap kinerja pegawai. Maneggio: Jurnal Ilmiah Magister Manajemen 2(2):170-183. https://doi.org/10.30596/ maneggio.v2i2.3667

Nofrita R. 2013. Pengaruh profitabilitas terhadap nilai perusahaan dengan kebijakan deviden sebagai variabel intervening. Jurnal Akuntansi 1(1):123.

Novyanti JS. 2015. Pengaruh motivasi kerja, lingkungan kerja, dan disiplin kerja terhadap kinerja pegawai pada Bappeda Provinsi Sulawesi Tengah. E-Jurnal Katalogis 3(1):105-115.

Ollukkaran BA, Gunaseelan R. 2012. A study on the impact of work environment on employee performance. International Journal of Management Research 2(2):71-85.

Permansari, R. 2013. Pengaruh Motivasi Dan Lingkungan Kerja Terhadap Kinerja Pt. Augrah Raharjo Semarang. Management Analysis Journal 2(2):1-9.

Prabandari KAT, Asri Dwija Putri IGAM. 2019. Kinerja dinas kependudukan dan pencatatan sipil Kabupaten Klungkung berdasarkan Metode Balance Scorecard. E-Jurnal Akuntansi 29(3):997-1011.https://doi.org/10.24843/ EJA.2019.v29.i03.p07 
Priarso MT, Diatmono P, Mariam S. 2019. The effect of transformational leadership style, work motivation, and work environment on employee performance that in mediation by job satisfaction variables in PT. Gynura Consulindo. Business and Entrepreneurial Review 18(2):165-176. https://doi.org/10.25105/ber.v18i2.5334

Putra D. 2013. Pengaruh akuntabilitas publik dan kejelasan sasaran anggaran terhadap kinerja manajerial satuan kerja perangkat daerah (Studi Empiris pada satuan kerja perangkat daerah Kota Padang). Jurnal Akuntansi 1(1):1-23. https:// doi.org/10.30588/jmp.v1i2.71

Rahmawanti NP, Swasto B, Prasetya A. 2014. Pengaruh lingkungan kerja terhadap kinerja karyawan (studi pada karyawan kantor pelayanan pajak pratama Malang Utara). Jurnal Administrasi Bisnis (JAB) 8(2):1-9.

Reiney HG. 2019. Handbook of Organizational Behavior: Work Motivation. Ed. ke-2. London: Taylor \& Francis Group.

Robbins SP. 2001. Pelaku Organisasi: Konsep, Kontroversi, Aplikasi:Jilid 1. Ed. ke-1. Hadyana Pujaatmaka dan Triyana Iskandarsyah, penerjemah. Jakarta : Prenhallindo.

Rosiana AM. 2013. Hubungan antara kondisi fisik rumah dengan kejadian tubekolosis paru. Unnes Journal of Public Health 2(1):1-9.

Sajangbati IA. 2013. Motivasi, disiplin, dan kepuasan pengaruhnya terhadap kinerja pegawai PT. Pos Indonesia (Persero) Cabang Bitung. Jurnal EMBA: Jurnal Riset Ekonomi, Manajemen, Bisnis Dan Akuntansi 1(4):667-678.

Selamat S, Heryanto H. 2019. Affecting factors in employee performance Koto Baru Sub-District, Dharmasraya District. Archives of Business Research 7(7):142-154.

Seo MG, Barrett LF, Bartunek JM. 2004. The role of affective experience in work motivation. Academy of Management Review 29(3):423-439. https://doi.org/10.5465/amr.2004.13670972

Serdamayanti. 2011. Manajemen Sumber Daya Manusia, Reformasi Birokrasi dan Manajemen Pegawai Negeri Sipil. Bandung: PT Refika Aditama.

Siahaan S, Bahri S. 2019. Pengaruh penempatan, motivasi, dan lingkungan kerja terhadap kinerja pegawai. Maneggio: Jurnal Ilmiah Magister Manajemen 2(1):16-30. https://doi. org/10.30596/maneggio.v2i1.3402
Sofyan DK. 2013. Pengaruh lingkungan kerja terhadap kinerja pegawai BAPPEDA. Industrial Enginering Journal 2(1):1-10.

Sudarmayanti. 2004. Sumber Daya Manusia dan Produktivitas. Bandung: Mandar Maju.

Sunarsi D, Wijoyo H, Prasada D, Andi D. 2020. Pengaruh lingkungan kerja terhadap kinerja karyawan pada PT Mentari Persada di Jakarta. Seminar Nasional Manajemen. hlm 117-123.

Sutrischastini A, Riyanto A. 2017. Pengaruh motivasi kerja terhadap kinerja pegawai kantor Sekretariat Daerah Kabupaten Gunungkidul. Kajian Bisnis STIE Widya Wiwaha 23(2):121-137. https://doi. org/10.32477/jkb.v23i2.209

Suwardi S, Utomo J. 2011. Pengaruh motivasi kerja, kepuasan kerja, dan komitmen organisasional terhadap kinerja pegawai (studi pada pegawai Setda Kabupaten Pati). Jurnal Analisis Manajemen 5(1):75-86.

Suwondo DI, Sutanto EM. 2015. Hubungan lingkungan kerja, disiplin kerja, dan kinerja karyawan.Jurnal Manajemen Dan Kewirausahaan 17(2):135144. https://doi.org/10.9744/jmk.17.2.145-154

Tanjung H. 2015. Pengaruh disiplin kerja dan motivasi kerja terhadap prestasi kerja pegawai pada dinas sosial dan tenaga kerja Kota Medan. Jurnal Ilmiah Manajemen Dan Bisnis 15(01):27-36.

Tinambunan D. 2010. Orang Batak Kasar Membangun Citra Karakter. R. Lumantoruan, editor. Jakarta: Elex Media Komputindo.

Twalib MH, Kariuki MM. 2016. Influence motivation on employee performance at Telkom Kenya Limited. Internasional Journal of Bisiness, Social Sciences, \& Education 2(11):421-431.

Wahyudi A, Suryono J. 2006. Analisis pengaruh gaya kepemimpinan, motivasi, dan lingkungan kerja terhadap kinerja pegawai. Jurnal Manajemen Sumber Daya Manusia 1(1):1-14.

Wantoro. 2013. Penggunaan warna biru pada desain website (studi kasus: Website Facebook, Unikom \& Barack Obama). Majalah Ilmiah Unikom 11(2):188-193.

Wibowo. 2015. Manajemen Kinerja. Ed. ke-4. Depok: Rajawali Pers.

Zahro UL, Serevina V, Astra M. 2017. Pengembangan lembar kerja siswa (LKS) Fisika dengan menggunakan strategi relating, experiencing, applying, cooperating, transferring (REACT) berbasis karakter pada pokok bahasan Hukum Newton. WAPFI: Wahana Pendidikan Fisika 2(1). https://doi.org/10.17509/wapfi.v2i1.4906 